\title{
ASSESSMENT OF CEMENT CONCRETE PARTIALLY REPLACED WITH POLYSTYRENE AND PLANTAIN PEEL ASH
}

\author{
0. O. Aderinola ${ }^{1, *}$, Y. Yusuf ${ }^{2}$ and 0. O. Omotayo ${ }^{3}$ \\ 1, 2, 3, DePT. OF Civil Engineering, Federal University of TeChnology, AKURE, ONDO STATE, NIGERIA \\ Email addresses: 1 olumuyiwaaderinola@gmail.com, 2 mohd.yusuf74@yahoo.in, \\ 3 ooomotayo@futa.edu.ng
}

\begin{abstract}
This study assessed the effect of partial replacement of cement with plantain peel ash (PPA) and Polystrene (POL) on the compressive strength of concrete as a means of managing waste. Concrete specimens were prepared with a mix ratio of 1:2:4 (cement: sand: granite) water/cement ratio of 0.6 , thereafter cement was partially replaced with PPA, POL and PPA/POL in increasing percentages of 5, 10, 15 and 20\% by weight. Physical, chemical and microstructural analyses were also conducted on the aggregates and materials used. Workability of the concrete specimens was observed to improve upon addition of PPA and POL separately but not with blended PPA/POL while compressive strength decreased with addition of the three compounds. The observed results can be attributed to the lack of sufficient cementitious properties in the materials, and hence, the study discourages the use of these materials as they do not significantly improve concrete strength.
\end{abstract}

Keywords: Plantain Peel Ash (PPA), Polystyrene (POL), Compressive Strength, Sustainable Waste Management

\section{INTRODUCTION}

Concrete is the most versatile heterogeneous construction material and one of the most viable materials for infrastructural development of any nation [1]. Concrete is a synthetic construction material made by mixing cement, fine aggregates, coarse aggregates and water in the proper proportions. Each of these components contributes to the strength of concrete [1]. In order to achieve strong, durable concrete, careful attention must be given to proportioning, mixing and compacting of the ingredients as well as selection of required grade of concrete [2]. Moreover, whenever there will be partial replacement of conventional concrete materials by other locally available materials, it is important to give careful consideration to selection of the most appropriate material [3].

Cement as an ingredient in concrete is one of the main construction materials widely used especially in developing countries. The increasing demand for cement, however, has necessitated a search for alternative materials that can replace cement. Coutinho [4] noted that this need is expected to be met by partial replacement of cement. The search for alternative binder materials over the years has led to the discovery of industrial by-products and agricultural wastes which can serve as cementitious materials. However, such materials are pozzolanic, studies have shown that they impart technical advantages to the resulting concrete and also enable larger quantities of cement replacement to be achieved [5]. Studies by Arikan [6] and Turanli et al. [7] indicate that substantial energy and cost savings can also result when industrial by-products are used as partial replacement to cement, due to the energy required for the production of Portland cement.

Incorporating wastes from industrial or agricultural processes in the construction industry can be borne out of the need to provide sustainable materials for construction. This is achieved either by searching for or incorporating new materials and products that are more environmentally friendly which results in the reduction of atmospheric carbon emission. Genezzini et al. [8] observed that the use of agricultural waste is an added advantage to the prevention of environment contamination, by means of proper waste disposal. Moreover, the presence of mineral admixtures from 
agricultural waste is known to bring about significant improvement in workability and durability of concrete. A geometric increase in the generation of solid wastes in Nigeria calls for a sustainable management options [9]. Plantain peels are agricultural by-products gotten from the plantain processing industry and their disposal has been found to have contributed to solid waste. Polystyrene waste also is a major contributor to the solid waste generated in the country. Their disposal contributes largely to environmental pollution, especially because they are non-biodegradable. These materials are normally dumped in landfills, rivers or dumpsites, thereby constituting serious environmental menace. With ever increasing production and consumption of plantain, the use of the waste in concrete offers a suitable alternative for managing the generated waste. With proper quality control, it is proposed that large amounts of waste and agricultural by-products can be incorporated into concrete, either in the form of blended cement or as mineral admixtures. This research therefore assesses the performance and suitability of polystyrene waste and plantain peel ash mixes as partial replacement of cement in the production of concrete.

A few researches have been conducted in the times past on the use of plantain peel ash as partial replacement of cement in concrete. Usman et al. [10] studied the effect of plantain peel ash on the mechanical properties of concrete and obtained optimum results at $10 \%$ replacement. Setting times were found to increase while compressive strengths were observed to decrease with cement replacement by PPA. Adetayo and Jubril [11] conducted a study on the effect of ripe and unripe plantain peel ash on the workability and compressive strength of concrete. It was observed that the workability of concrete increased with addition of both ripe plantain peel ash (RPPA) and unripe plantain peel ash (UPPA). It was also noted that both RPPA and UPPA contribute to late strength development of concrete, and that better performance is observed with RPPA. Ahmad and Ado [12] in a study observed that ripe plantain peel ash decrease the strength of concrete. Cadere et al. [13] investigated engineering properties of concrete with polystyrene and observed that workability of fresh concrete is improved and density decreased with polystyrene, and hence is suitable for production of lightweight concrete. Another study showed that thermal insulating properties of concrete can be improved upon with the use of polystyrene [14].

\section{MATERIALS AND METHODS}

The materials used in this research are Ordinary Portland Cement (Dangote brand), sand (fine aggregate), granite (coarse aggregate), clean water, Polystyrene (POL) and Plantain Peel Ash (PPA). These materials were obtained from the Akure metropolis, apart from polystyrene which was obtained from a construction site in Lagos.

\subsection{Sample Collection}

Plantain peel used to produce the PPA was procured from a plantain chips company within Akure metropolis. The peels were sun-dried, pulverized and burned in a muffle furnace at a temperature of $750^{\circ} \mathrm{C}$ for about 2 hours in order to remove moisture and preserve its amorphous form. POL, on the other hand, was procured from Lagos and shredded into tiny particles.

\subsection{Physical Analysis}

Particle size distribution analysis (with minimum sieves size $75 \mu \mathrm{m}$ ) was carried out on the fine aggregate obtained. Meanwhile, aggregate crushing value (ACV) and aggregate impact value (AIV) tests were done for the coarse aggregates according to BS 812-110 [15] and BS 812-112 [16] respectively. The particle size distribution curve for the fine aggregate used was plotted. Moisture content and soundness tests were also carried out on these materials.

\subsection{Chemical Analysis}

Chemical tests were carried out on the PPA and POL to determine their chemical properties. Chemical analyses conducted include X-Ray fluorescence analysis and scanning electron microscopic analysis.

\subsection{X-Ray Fluorescence Analysis}

$\mathrm{X}$-ray fluorescence (XRF) spectrometry (XRF machineModel $X$-supreme 8000 by Oxford instrument) was used in the determination of the various percentages of oxide present in the ash and the powder. Mini Pal 4 Energy dispersive X-ray fluorescence (XRF) bench-top spectrometer was also used to perform nondestructive chemical analysis of elemental oxides present in the different wastes used. The PPA and POL were loaded into the sample holder and placed in the appropriate sample tray. The test was carried out by bombarding the samples with high energy X-rays which resulted into emission of characteristics secondary X-rays. Using silicon drift detector, the elemental analysis and oxide composition were 
determined and printed out through the attached computer and printer.

\subsection{Scanning Electron Microscopic Analysis}

In carrying out SEM analysis, the paste samples (of about $25 \mathrm{~mm}$ diameter) were prepared to fit into the specimen chamber and they were mounted rigidly on the specimen stub. Their surfaces were polished to an ultra-smooth surface and were coated with carbon. Secondary electron detectors were used, and the data were displayed by a computer device.

\subsection{Test and Analysis of Concrete Specimens}

Using a mix ratio of $1: 2: 4$ and water/cement ratio of 0.6 , concrete cubes with a dimension of $150 \mathrm{~mm} \times$ $150 \mathrm{~mm} \times 150 \mathrm{~mm}$ were produced by partially replacing OPC with PPA, POL, and PPA/POL at 0, 5, 10, 15 and $20 \%$. The samples were cured in water for 7 , 21,28 and 56 days and subjected to compression strength tests in accordance with BS EN 12390-3 [17]. The constituent materials were batched by weight as shown in Table 1 . The mix produced with only cement as binder served as the control mix. Summary of the mix design is as presented in Table 2. Also, various cement pastes with mix ratio 1:6 (cement: sand) of 50 $\mathrm{mm} \times 50 \mathrm{~mm} \times 50 \mathrm{~mm}$ dimension were made with the cement partially replaced with PPA and POL at $0 \%$ and PPA/POL at $10 \%$. The pastes were cured for 28 days duration and then analyzed using scanning electron microscope (SEM).

\section{RESULTS AND DISCUSSION}

\subsection{Physical and Chemical Behaviour of Materials used in the study}

The results of the particle size distribution test for sand (fine aggregate) is shown in Figure 1 . This result showed that the sand was well graded as the Uniformity Coefficient $\mathrm{C}_{\mathrm{u}}$ and Coefficient of Gradation $\mathrm{C}_{\mathrm{c}}$ both fall within acceptable range. The results of the ACV and AIV for the granites chippings were $30.48 \%$ and $19.78 \%$ respectively as shown in Table 2 , which are adequate for concrete of good impact resistance according to BS 882 [18]. The result of the chemical composition test performed on the OPC, PPA and POL is presented in Table 3. $\mathrm{CaO}, \mathrm{SiO}_{2}, \mathrm{Al}_{2} \mathrm{O}_{3}$ and $\mathrm{Fe}_{2} \mathrm{O}_{3}$ are major constituents of cement and any substance that must exhibit considerable cementitious properties [19]. However, it can be seen from the results that unlike OPC which contains $62 \% \mathrm{CaO}, 22 \% \mathrm{SiO}_{2}$ and $3.11 \% \mathrm{Al}_{2} \mathrm{O}_{3}$, the ash and the shredded polystyrene are both lacking in these compounds. Lack of these compounds in the PPA and POL showed lower cementitious action than OPC and consequently inhibited pozzolanic properties. However, the contents of $\mathrm{MgO}$ and $\mathrm{Fe}_{2} \mathrm{O}_{3}$ in the ash are all within similar ranges contained in an Ordinary Portland Cement as seen in Table 3. Other oxides found in the ash that are of significance are $\mathrm{K}_{2} \mathrm{O}$ and chlorine, which may combine to form $\mathrm{KCl}$.

\subsection{Slump test}

Tables 4 and 5 show the results of the slump test and compaction factor test performed on fresh concrete produced with PPA, POL and POL/PPA respectively. It was observed that the slump value of the concrete increased with addition of PPA and POL, except of fresh concrete with the blended POL/PPA mix, which exhibit decrease with slump value with PPA/POL addition. From the results, it is obvious that a blend of PPA/POL with concrete greatly reduces the workability of the concrete, while a separate addition of each of these materials results in improved workability.

Table 1: Summary of Quantities of Materials for the Mix Design

\begin{tabular}{lccccc}
\hline \multirow{2}{*}{ Materials } & \multicolumn{5}{c}{ Quantities (kg) } \\
\cline { 2 - 6 } & $\begin{array}{c}\text { OPC } \\
(100 \%)\end{array}$ & PPA/POL (5\%) & PPA/POL (10\%) & PPA/POL (15\%) & PPA/POL (20\%) \\
\hline Cement (kg) & 12.50 & 11.88 & 11.25 & 10.63 & 10.00 \\
PPA (kg) & 0.00 & 0.31 & 0.63 & 0.94 & 1.25 \\
POL (kg) & 0.00 & 0.31 & 0.63 & 0.94 & 1.25 \\
Water (kg) & 7.50 & 7.50 & 7.50 & 7.50 & 7.50 \\
Sand (kg) & 25.00 & 25.00 & 25.00 & 25.00 & 25.00 \\
Granite & 50.00 & 50.00 & 50.00 & 50.00 & 50.00 \\
Water/Cement Ratio & 0.60 & 0.60 & 0.60 & 0.60 & 0.60 \\
\hline
\end{tabular}




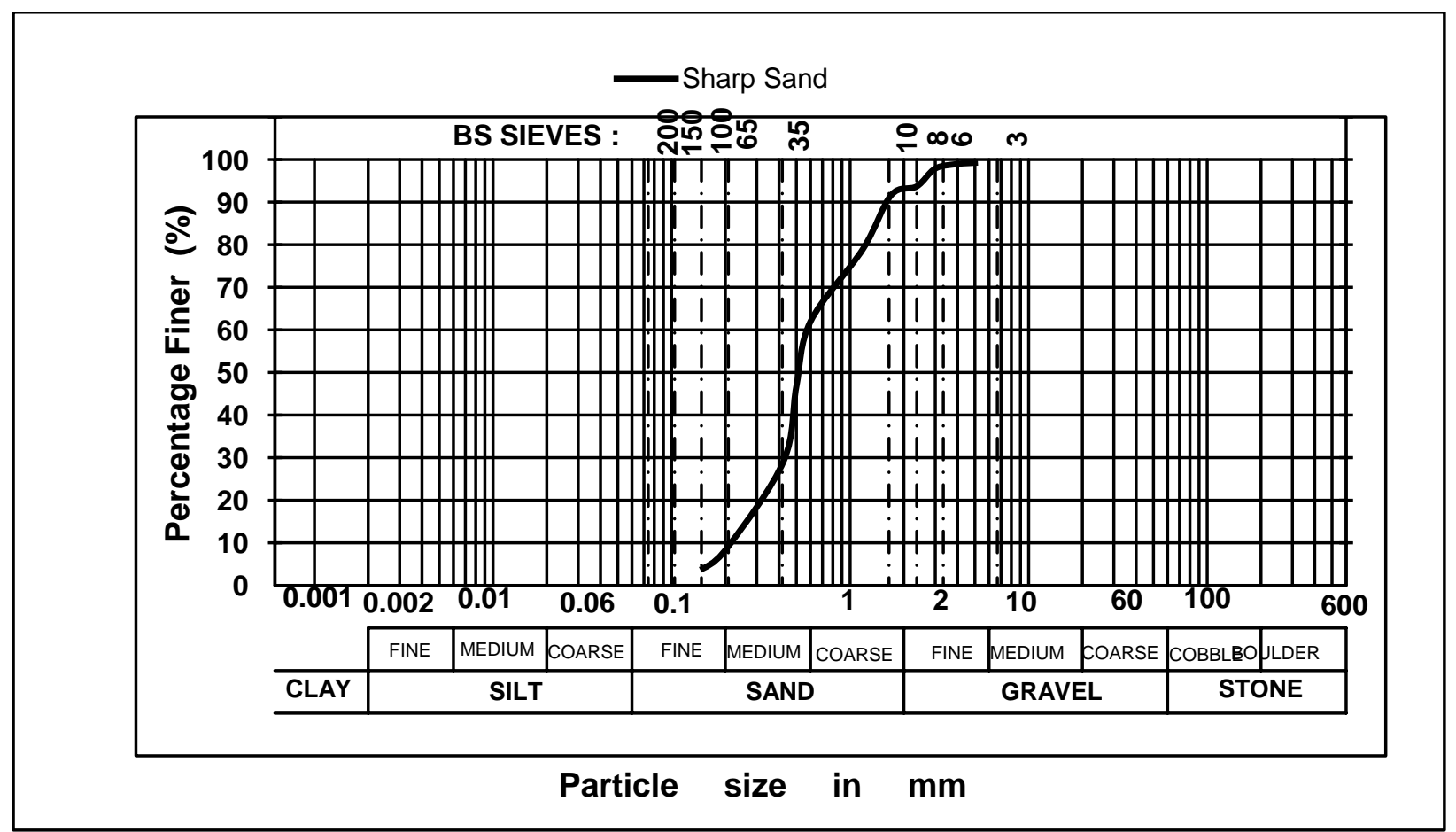

Figure 1: Particle Size Distribution Curve for fine aggregates

Table 2: Physical Properties of the Materials Used

\begin{tabular}{llllll}
\hline $\begin{array}{l}\text { Physical Properties of } \\
\text { Materials }\end{array}$ & $\begin{array}{l}\text { Fine } \\
\text { Aggregate } \\
\text { (Sand) }\end{array}$ & $\begin{array}{l}\text { Coarse } \\
\text { Aggregate } \\
\text { (Granite) }\end{array}$ & $\begin{array}{l}\text { Shredded } \\
\text { Polystyrene } \\
(\mathrm{POL})\end{array}$ & $\begin{array}{l}\text { Plantain peel } \\
\text { Ash (PPA) }\end{array}$ & $\begin{array}{l}\text { Ordinary } \\
\text { Portland Cement } \\
(\mathrm{OPC})\end{array}$ \\
\hline Bulk Density $\left(\mathrm{g} / \mathrm{cm}^{3}\right)$ & 1.788 & - & - & - & - \\
Moisture Content (\%) & 0.47 & - & - & - & - \\
Silt/Clay Content (\%) & 5.56 & - & 100 & 100 & 99.72 \\
Fineness content (\%) & - & - & $>10$ & $<10$ & $<10$ \\
Soundness (mm) & - & - & 1.07 & 2.65 & 3.13 \\
Specific Gravity & 2.64 & 2.61 & - & - & - \\
AIV (\%) & - & 19.78 & - & - & - \\
ACV (\%) & - & 30.48 & - & - & - \\
Water Absorption (\%) & - & 0.93 & - & - & - \\
Uniformity coefficient, Cu & 1.75 & - & - & - & - \\
Coefficient of gradation, Cc & 1.08 & - & & & \\
\hline
\end{tabular}

Table 3: Chemical Composition of PPA, POL and OPC

\begin{tabular}{ccccc}
\hline Chemical Oxide & Approximate Limits of Compounds (\%) & PPA (\%) & OPC (\%) & POL (\%) \\
\hline Calcium Oxide $(\mathrm{CaO})$ & $60-67$ & 7.89 & 62.00 & N/A \\
Silica $\left(\mathrm{SiO}_{2}\right)$ & $17-25$ & 7.84 & 22.00 & N/A \\
Alumina $\left(\mathrm{Al}_{2} \mathrm{O}_{3}\right)$ & $3.0-8.0$ & 2.65 & 3.11 & N/A \\
Ferric Oxide $\left(\mathrm{Fe}_{2} \mathrm{O}_{3}\right)$ & $0.5-6.0$ & 1.24 & 4.65 & N/A \\
Magnesium Oxide $(\mathrm{MgO})$ & $0.1-4.0$ & 0.38 & 2.06 & N/A \\
\hline
\end{tabular}

Table 4: Slump Test Values for PPA, POL and Binary Blended Cement Concrete

\begin{tabular}{cccc}
\hline $\begin{array}{c}\text { Percentage Replacement } \\
(\%)\end{array}$ & $\begin{array}{c}\text { PPA Slump Height } \\
(\mathrm{mm})\end{array}$ & $\begin{array}{c}\text { POL Slump Height } \\
(\mathrm{mm})\end{array}$ & $\begin{array}{c}\text { PPA+POL Slump Height } \\
(\mathrm{mm})\end{array}$ \\
\hline 0 & 58 & 58 & 58 \\
5 & 65 & 72 & 55 \\
10 & 68 & 75 & 52 \\
15 & 76 & 76 & 50 \\
20 & 82 & 80 & 50 \\
\hline
\end{tabular}


Table 5: Compaction Factor for PPA, POL and Binary Blended Cement Concrete

\begin{tabular}{cccc}
\hline OPC Replacement (\%) & $\begin{array}{c}\text { Compaction factor, } C_{f} \\
(\text { PPA })\end{array}$ & $\begin{array}{c}\text { Compaction factor, } C_{f} \\
(P O L)\end{array}$ & $\begin{array}{c}\text { Compaction factor, } C_{f} \\
\text { (PPA + POL) }\end{array}$ \\
\hline 0 & 0.80 & 0.80 & 0.80 \\
5 & 0.85 & 0.85 & 0.85 \\
10 & 0.83 & 0.87 & 0.86 \\
15 & 0.81 & 0.80 & 0.90 \\
20 & 0.86 & 0.90 & 0.90 \\
\hline
\end{tabular}

\subsection{Compressive Strength Test}

The results obtained from the compressive strength test performed on the hardened concrete cubes are presented in Figures 2 to 4 . Results presented in Figure 2 shows that the compressive strength of concrete decreased with PPA content replaced. Similar trend was observed with POL and blended PPA/POL. This low strength development can be attributed to the very low levels of cementitious compounds, especially $\mathrm{SiO}_{2}, \mathrm{Al}_{2} \mathrm{O}_{3}$ and $\mathrm{Fe}_{2} \mathrm{O}_{3}$, in both PPA and POL. This trend is similar to that observed in previous researches [10 - 12].

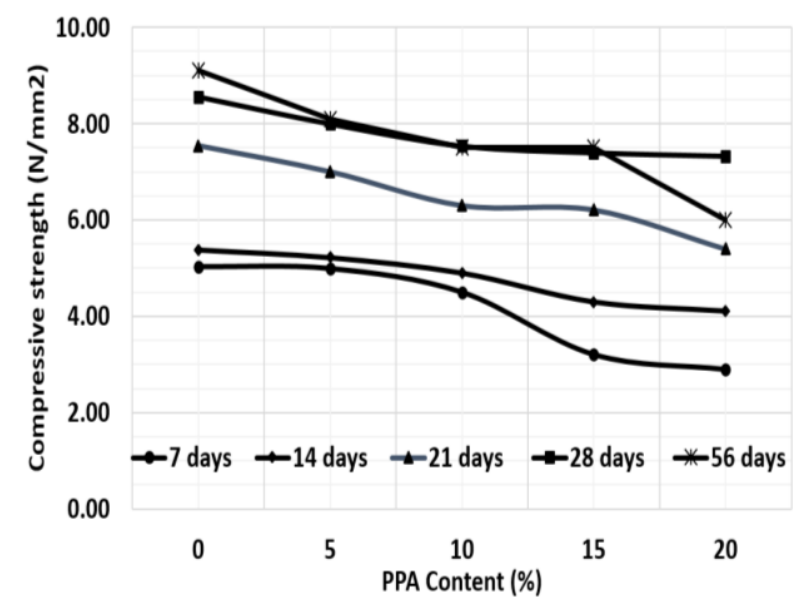

Figure 2: Variation of PPA with Compressive Strength of Concrete

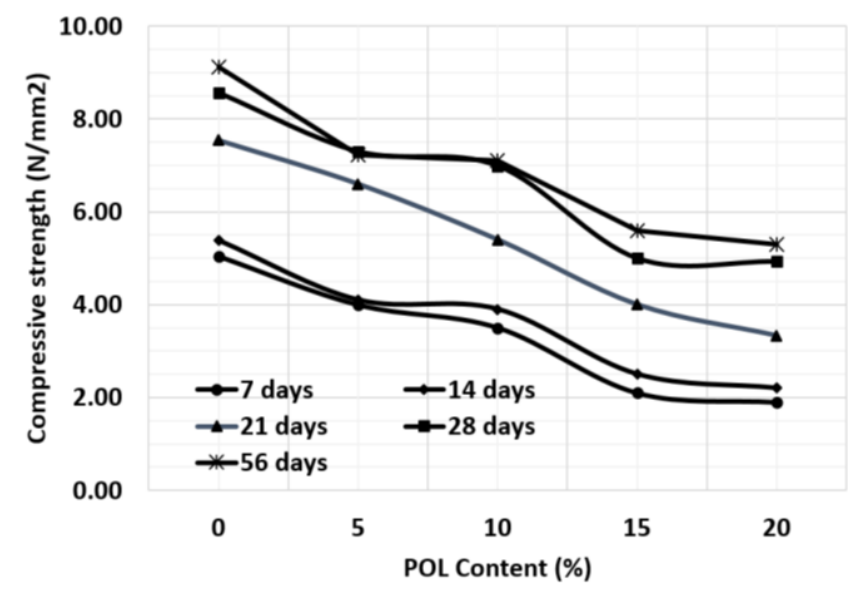

Figure 3: Variation of POL with Compressive Strength of Concrete

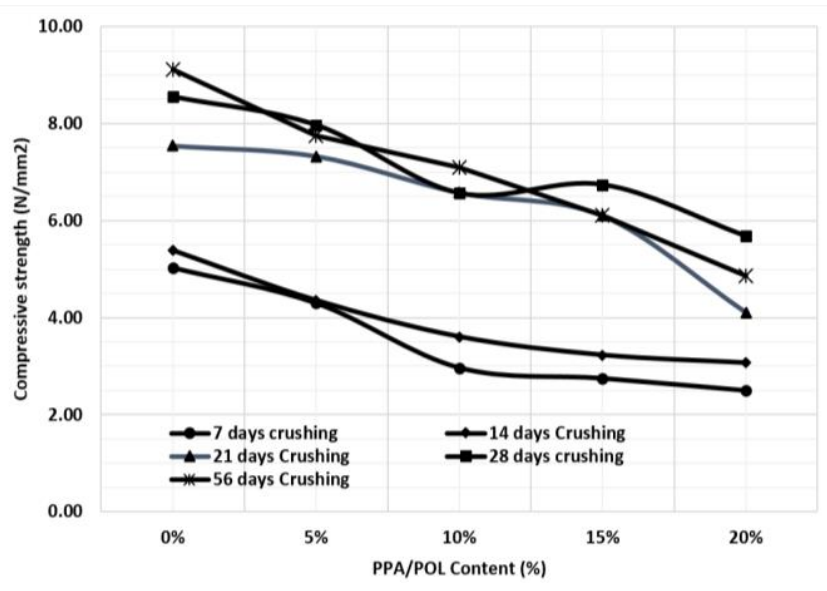

Figure 4: Variation of Blended POL/PPA with Compressive Strength of Concrete

\subsection{Scan Electron Microscopy}

The results of the SEM micrographs of the developed samples of OPC, OPC/PPA, OPC/PPA and OPC/PPA/POL are shown in Figures 5 to 7 respectively. From Figure 5, the particles were observed to be closely packed with minute degree of looseness. This is caused by the presence of $100 \%$ cement which forms a very strong bond in its dry state. Figure 6(a) shows that the particle size of the crystals were observed to be moderately large in the sample having $90 \%$ cement and $10 \%$ PPA composition. Compared to the control concrete, there was lower interfacial bonding between the OPC and PPA particles. Figure 6(b) also shows similar trend with Figure 6(a), upon addition of $10 \% \mathrm{POL}$ to concrete. POL grains introduced into the concrete matrix resulted in the creation of voids in the concrete at the cement/POL interface. The presence of voids and loose packing of the elements resulted in weaker bonding observed between the elements, and hence corresponding decrease in compressive strength. This trend is similar to that observed in previous research [20]. Figure 7 shows the scanning electron micrograph (SEM) of the sample with $90 \%$ OPC and $10 \%$ PPA/POL. As seen in the figure, certain areas of the concrete have large concentration of OPC particles compared to other areas having concentration of PPA/POL particles. This can be attributed to improper blending of the PPA and 
POL with the OPC in the mix. Hence, very loose packing of the particles is observed, with very weak bonding as well. This therefore explains the low strength observed in the use of this mixture compared to the other mixtures used in this study.

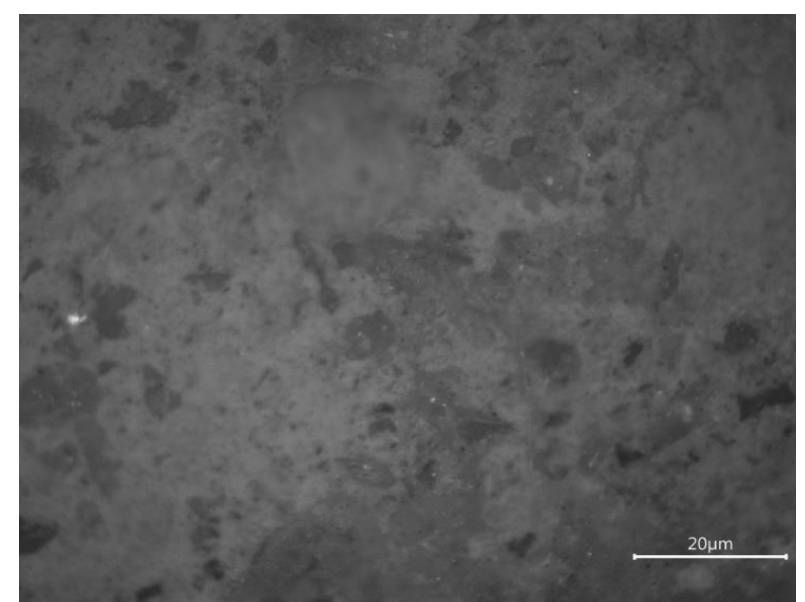

Figure 5: Micrograph of Developed Sample with 260 Magnification of OPC

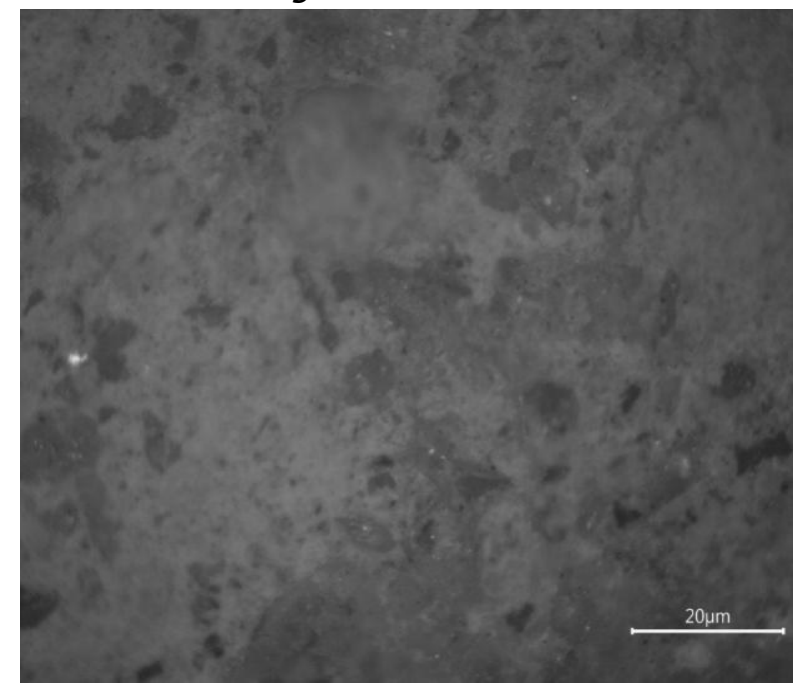

Figure 6: (a) Micrograph of Developed Sample of $O P C / P P A$

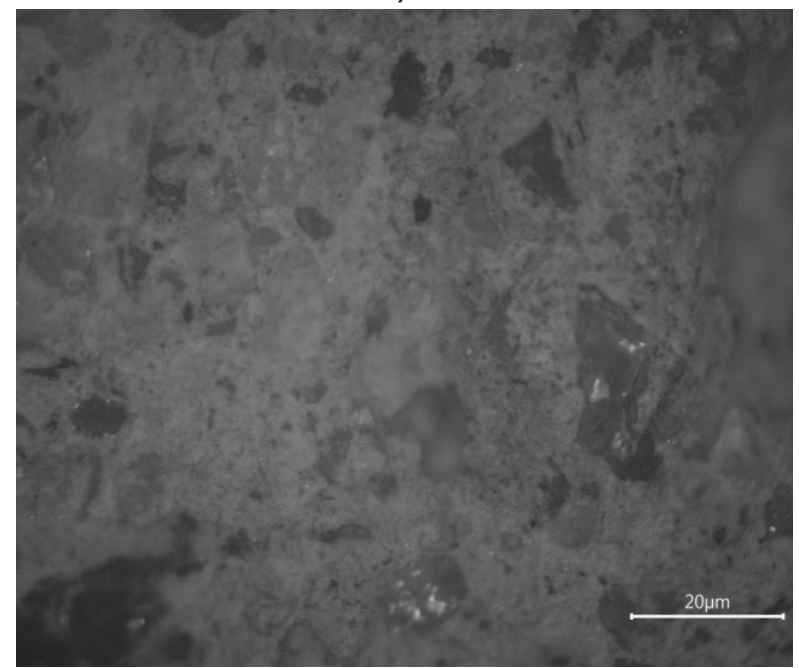

(b) Micrograph of Developed Sample of OPC/POL

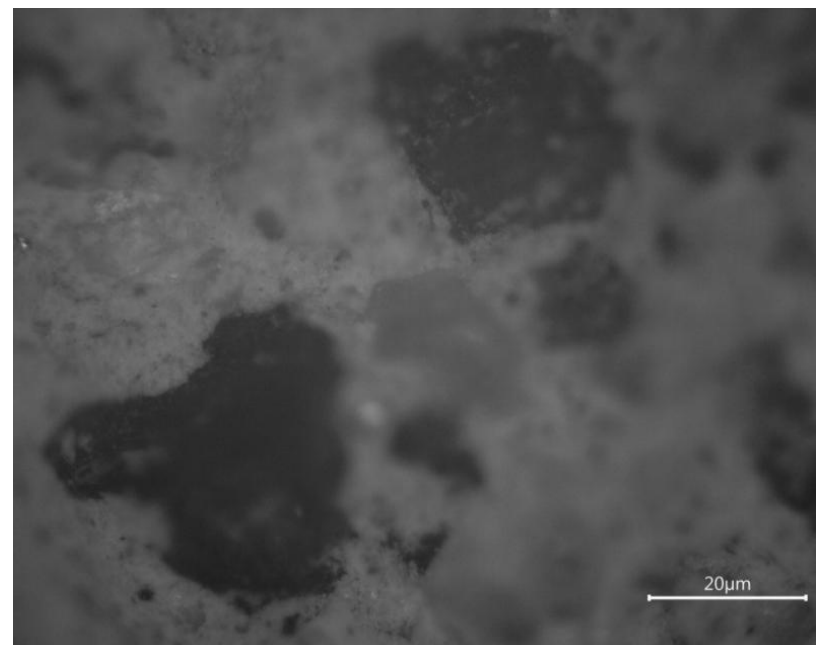

Figure 7: Micrograph of Developed Sample with 260 Magnification of OPC/PPA/POL

\section{CONCLUSION}

From the study, the following conclusions can be made:

(a) The oxide composition analysis shows that POL is a non-pozzolanic material with no calcium oxide ( $\mathrm{CaO})$ content and no silicon oxide $\left(\mathrm{SiO}_{2}\right)$ content, while the plantain peel ash (PPA) is a nonpozzolanic material with a little amount of silica $\left(\mathrm{SiO}_{2}\right)$ component.

(b) The workability of concrete improved with PPA and POL when added separately, but reduced when combined.

(c) The compressive strength of concrete reduces with increasing percentages of PPA, POL and blended PPA/POL content.

(d) The addition of PPA and POL to ordinary Portland cement concrete did not improve the microstructural property of the concrete.

\section{REFERENCES}

[1] Gambir, G. (2004). Use of Cement components and Concrete Composites produced with pozollans. Cement and Concrete Composite, 349-356.

[2] Dale, P., Bentz, M. A., \& Peltz, J. W. (2009). EarlyAge Properties of Cement-Based Materials: II. Influence of Water-to-Cement Ratio. ASCE Journal of Materials in Civil Engineering, 21(9): 512-517.

[3] Wankhede, P. R., \& Fulari, V. A. (2014). Effect of Fly Ash on Properties of Concrete, International Journal of Emerging Technology and Advanced Engineering, 4(7): 284-289. 
[4] Coutinho, J. S. (2003). The Combined Benefits of CPF and RHA in Improving the Durability of Concrete Structures, Cement and Concrete Composites, 25: 51-59.

[5] Hossain, K. M. (2003). Blended Cement using Volcanic Ash and Pumice. Cement and Concrete Research, 33: 1601-1605.

[6] Arikan, M. (2004). Feasibility Analysis of Manufacturing High Performance Ecological Cement in Turkey. Journal of Building and Environment, 39: 1125-1130.

[7] Turanli, L., Uzal, B., \& Bektas, F. (2004). Effect of Material Characteristics on the Properties of Blended Cements Containing High Volumes of Natural Pozzolans. Cement and Concrete Research, 34: 2277-2282.

[8] Genezzini, C., Zerbino, R., Ronco, A., \& Batic, O. (2003). Hospital Waste Ashes in Portland Cement Mortars. Cement and Concrete Research, 1643 1650.

[9] Babayemi, J. O., \& Dauda, K. T. (2009). Evaluation of Solid Waste Generation, Categories and Disposal Options in Developing Countries: A Case Study of Nigeria. Journal of applied science and environmental management, III(13): 83-88.

[10] Usman, A., Bala, N., \& Bashiru, M. (2018). Effect of Plantain Peel Ash (PPA) on the Mechanical Properties of Concrete. Noble International Journal of Scientific Research, 2(03): 11-18.

[11] Adetayo, O. A., \& Jubril, O. (2019). Effect of Ripe and Unripe Plantain Peel Ash on Concrete Workability and Compressive Strength. FUOYE Journal of Engineering and Technology, 4(1): 145-148.

[12] Ahmad, D. A. \& Ado, M. (2016). Investigation in to the Use of Plantain Peels Ash as an
Admixture in Concrete. International Journal of Engineering Science and Computing, 6(5): 5377 - 5380.

[13] Cadere, C. A., Barbuta, M., Rosca, B., Serbanoiu, A. A., Burlacu, A., \& Oancea, I. (2018). Engineering Properties of concrete with polystyrene granules. Procedia Manufacturing (22): 288-293.

[14] Kharun, M. \& Svintsov, A. P. (2017). Polystyrene concrete as the structural thermal insulating material. International Journal of Advanced and Applied Sciences, 4(10): 40-45.

[15] BS 812-110 (1990). Testing aggregates - Part 110: Methods for determination of aggregate crushing value (ACV). British Standards Institute (BSI).

[16] BS 812-112 (1990). Testing aggregates - Part 110: Methods for determination of aggregate impact value (AIV). British Standards Institute (BSI).

[17] BS EN 12390-3 (1990). Testing hardened concrete- Part 3: Compressive Strength of Test Specimens. British Standards Institute (BSI)

[18] BS 882 (1992). Specification for aggregates from natural sources for concrete. British Standards Institute (BSI).

[19] Neville, A. M., \& Brooks, J. J. (2010). Concrete technology (2nd ed.). Essex, England: Pearson Education Limited.

[20] Petrella, A., Mundo R. D., \& Notarnicola, M. (2020). Recycled Expanded Polystyrene as Lightweight Aggregate for Environmentally Sustainable Cement Conglomerates. Materials, 13(988): 1-17. 